\title{
Do children see the danger in dangerous? Grade 4, 6, and 8 children's reading of morphologically complex words
}

\author{
S. HÉLÈNE DEACON \\ Dalhousie University \\ RACHEL WHALEN \\ McGill University \\ JOHN R. KIRBY \\ Queen's University at Kingston
}

\section{ADDRESS FOR CORRESPONDENCE}

S. Hélène Deacon, Department of Psychology, Life Sciences Centre, Dalhousie University, Halifax, NS B3H 4J1, Canada. E-mail: helene.deacon@dal.ca

\begin{abstract}
We examined whether Grade 4, 6 , and 8 children access the base form when reading morphologically complex words. We asked children to read words varying systematically in the frequency of the surface and base forms and in the transparency of the base form. At all grade levels, children were faster at reading derived words with high rather than low base frequencies when the words were of low surface frequency. Effects of the frequency and transparency of the base form on word reading accuracy occurred only in Grades 4 and 6 . The results add to the growing body of evidence that children access the morphological structure of the words that they encounter in print.
\end{abstract}

Derivational morphology has an important place in children's oral and written language development across the upper elementary school years. Derived words are those for which the addition of an affix typically signals a change in word type (e.g., from the noun magic to the adjective magical) and brings with it a degree of change in meaning. Inflected words also contain affixes, but these typically mark more minor alterations, such as tense and number. Anglin (1993) found that children's oral vocabulary grows by about 20 words per day between Grades 1 and 5, of which just under half are derived words. Nagy, Osborn, Winsor, and O'Flahavan (1993) estimated that 40\% of unfamiliar words that average Grade 5 students encounter in print are derived from more frequent words (see also Nagy \& Anderson, 1984). Over the last decade, researchers have begun to demonstrate that

(C) Cambridge University Press 2011 0142-7164/11 \$15.00 
children's reading of individual words is affected by their morphological structure (e.g., Mann \& Singson, 2003). The present study builds on this recent line of work by examining potential interactions in the effects of morphological structure on children's reading.

It is clear that morphological structure has an impact on children's reading as early as Grade 2. Carlisle and Stone (2005) asked children to read two- and onemorpheme words (e.g., shady and lady, respectively) matched on spelling, word length, and word frequency. Children in both lower (Grades 2 and 3) and upper elementary (Grades 5 and 6) grades were more accurate at reading derived than control words. For the younger children, this difference was also reflected in faster responses for the derived forms. Carlisle and Stone (2005) suggested that accessing a base morpheme can facilitate the reading of transparent morphologically complex forms.

Similar evidence has come from manipulations of the base frequency of morphologically complex words. The concept of base frequency forces the distinction between (at least) two separable frequency counts for morphologically complex words. The first is the frequency of the whole word form, known as surface frequency (e.g., magician). The second is the frequency of the base of the derived form (e.g., magic for magician). In an innovative first attempt to manipulate base frequency, Carlisle (2000) asked Grade 3 and 5 children to read high and low surface frequency words that had similarly high base frequencies. She reasoned that if children were accessing the base when they were reading the words, then the high level of base frequency might overcome differences emerging from surface frequency variations (see, e.g., Mann \& Singson, 2003; Carlisle \& Stone, 2005). This was not the case; children were more accurate in reading words with higher surface frequencies than those with lower surface frequencies (for similar results with children in Grades 4 and 6, see Carlisle \& Katz, 2006). This result suggests that children's sensitivity to the morphological structure of words is not adequate to offset differences brought on by the surface frequencies.

Studies varying base frequency of words have been more successful in demonstrating that children might access the base when reading morphologically complex words. Mann and Singson (2003) found that Grade 3 to 6 children were more accurate in reading words with high than with low base frequencies, even though the words had similar surface frequencies. Similar results emerge from a different comparison. Carlisle and Stone (2005) found that the frequency of the base contributed significantly to the accuracy (but not speed) with which Grade 4 and 5 children read low surface frequency derived words (e.g., queendom). These findings did not emerge with their younger sample (Grades 2 and 3). The results of these two comparisons suggest that children's reading accuracy is influenced by the frequency of the bases within the words that they encounter, and that this effect might be more powerful in the upper elementary school grades.

Another feature of the base that has been manipulated is opacity, or the phonological transparency of the base form in the derived form (e.g., magic in the transparent form magical and the opaque form magician). The premise here is that, if children access the morphological structure of the words that they read, they should be more accurate in reading words for which the base form is 
phonologically and orthographically transparent than when it is not. Carlisle (2000) found precisely this effect in her study of Grade 3 and 5 children. Mann and Singson (2003) found a similar pattern of results with children in Grades 3 and 4 (that did not emerge in their sample of children in Grades 5 and 6). Carlisle and Stone (2005) extended this work to older students by showing that the opacity of the base form affected reading accuracy across ages 10 to 15 years and speed of reading for the younger participants. Such results have been interpreted as suggesting that children access the morphological structure, the base form in particular, of words that they encounter in print.

Previous studies have demonstrated evidence for the impact of morphological structure on children's reading by manipulating features of the base form (frequency and phonological transparency). We build on this work by investigating the impact of these two variables in a design that permits examinations of potential interactions between these factors, as well as with that of surface frequency. The inclusion of surface frequency allows us to examine the possibility that the impact of the frequency of the base form might be greater for words with low surface frequencies than for those with high surface frequencies, which is a question raised by Mann and Singson (2003) and Carlisle and Katz (2006). Similarly, we examine whether the impact of the transparency of the morphological structure (as reflected by the opacity variable) is greater for words of low than of high surface frequency. It is possible that words of high surface frequency might be more likely to be recognized as whole word forms, thereby lowering the opportunity for an impact of the structure of the base. The inclusion of base frequency, surface frequency, and opacity variables in one design permits the investigation of these potential interactions.

We examine the effects of these variables in the reading of derived words in a cross-sectional design with children in Grades 4, 6, and 8. Following on Carlisle and Stone (2005), we conduct this study with a methodology that allows us to collect response time and accuracy data. We make no directional predictions about reaction time results, given Tyler and Nagy's (1989) discussion of the potentially opposing influences of morphological structure on response time. This caution is heightened by the relative paucity of research on morphological effects on children's reading times (for an exception, see Carlisle \& Stone, 2005).

Given prior work demonstrating main effects of transparency and base frequency with children (e.g., Carlisle, 2000), we predict the emergence of these effects in the present paradigm. It is more difficult to make predictions about interactions given the focus of prior developmental research on the manipulation of single variables. Research with adults (e.g., Taft, 1979) suggests that participants are faster at making lexical decisions to words with low than with high base frequencies when the words had low surface frequencies. We expect to find this to be the case even with our developing readers, although, of course, the results for word reading might differ from those for lexical decision. This is based on the premise that high frequency words might be read by whole word retrieval that bypasses morphological segmentation or sensitivity to morphological structure. Similarly, it is possible that the effect of transparency of the base will vary across the frequency manipulation. The manipulation in the same paradigm of base frequency, opacity, and surface frequency will provide insight into the effects of morphological structure on Grade 4, 6, and 8 children's reading of derived words. 


\section{METHOD}

\section{Participants}

This study included a total of 85 participants, with 30 Grade 4 students, 31 Grade 6 students, and 24 Grade 8 students who were recruited from a rural area of eastern Canada. There were 18 girls in each of Grades 4 and 6, and 12 in Grade 8. The children had mean ages of 9 years, 7 months (9;7, $S D=6.7$ years), 11;6 ( $S D=6.1$ years), and 14;8 ( $S D=4.3$ years) in Grades 4,6 , and 8 , respectively. Participants had average reading ability according to their performance on the word identification and word attack subtests from the Woodcock Reading Mastery Tests-Revised (Woodcock, 1998). Standardized scores for the word identification were $98.17(S D=14.83), 100.61(S D=11.02)$, and $96.58(S D=7.02)$, for each grade, respectively. Scores for word attack were $105.20(S D=11.18), 101.97$ $(S D=11.19)$, and $98.12(S D=7.09)$, for each grade, respectively. English was the first language for all participants.

\section{Materials}

A set of 64 two morpheme derived words was selected, with 8 words in each of eight conditions. These eight conditions arose from a $2 \times 2 \times 2$ matrix: high or low base frequency, high or low surface frequency, and transparent or opaque base form. These words are listed in Appendix A.

We selected words for the high and low surface frequency conditions on the basis of their frequency in the Zeno Word Frequency Guide (1995; for the appropriateness of this corpora, see Lee, 2003). Three was the maximum value for low frequency items, whether this was of the base or for surface frequency, and 50 was the minimum value for the high frequency items. Opacity was defined by changes in the phonological structure of the word from the base to the derived forms. Opaque items included both those with phonological shifts only (e.g., heal-health) and those with both a phonological and an orthographic shift (e.g., agile-agility). We included both types due to challenges in meeting the many requirements for item selection.

We attempted to control for several factors. We ensured that items for each of the low base frequency conditions were similar in base frequency, as were those for the high base frequency conditions ( $p s>.34)$. The same analyses were conducted for the surface frequency. Surface frequencies were similar across each of the low surface frequency conditions $(p s>.47)$. We attempted to ensure the same balancing for the high surface frequency conditions. We were able to achieve this within the transparent and opaque conditions ( $p$ s > .69), but not across these conditions. Words were selected so that the opaque items had a higher frequency, thereby biasing results against the expected direction (of higher accuracy and increased speed for the transparent items compared to opaque items). The number of letters ( $p$ s > .36), the number of sounds ( $p$ s > .46), and the number of syllables ( $p s>.47)$ in each word read were similar across the conditions. There were similar numbers of items with solely phonological changes across conditions $(p s>.72)$. 


\section{Procedure}

We tested children individually in a quiet place in their schools. The derived word reading task was administered as a part of a larger battery of reading and language measures. Participants were fitted with an Apex270 Dynamic Headset microphone. They sat in front of a Dell Latitude D800 laptop computer with a 15-in. monitor. They were asked to read a set of words presented on a computer screen and, while doing so, to emphasize accuracy over speed. They were asked to be cautious to not say "umm" or other pause fillers, as this would trigger the microphone. They were given three practice words (cat, tree, and jumper).

The 64 words were presented in four blocks of 16, with 2 words from each of the 8 conditions in each block. Words were randomized within each block by the presentation program (DirectRT; Jarvis, 2000). The words were shown on a black computer screen in white 40 point Arial font. A white cross was presented for $1 \mathrm{~s}$ before each word. Each word remained on the screen for $1 \mathrm{~s}$ after it was named by the participant, as pilot testing revealed that immediate disappearance disrupted participants' reading.

Participants' response time was measured using the voice-activated microphone and was recorded directly by the computer. The accuracy of the participants' pronunciation was recorded by the experimenter. The experimenter also recorded the accuracy of the response time capture, as the microphone was sensitive to pause fillers such as "um" and false starts.

\section{RESULTS}

We assessed children's accuracy in reading each of the words and the time taken to pronounce each of the words. The first analyses reported below have accuracy as the dependent variable and the second have response time as the dependent variable. The analyses indicate reasonable reliability with a Cronbach $\alpha$ of 0.95 across all 64 items (range $=0.55-0.85$ within each condition). Accuracies and response times for each item averaged across all participants are shown in Appendix A.

\section{Analyses of accuracy of word reading}

The mean accuracies of children's pronunciations of the words in each condition are shown in Table 1. There is evidence of ceiling effects at both Grades 6 and 8. In order to reduce the possibility that any results obtained might be explained by ceiling effects, we focused analyses on those cells for which the addition of one standard deviation to the mean did not overlap with the maximum score of 1 . This allowed us to examine the effects of all three within-subject variables at Grade 4, and of the base frequency variable for low surface frequency items at Grade 6 . We did not conduct statistical analyses of the accuracy data at Grade 8 due to the prevalence of ceiling effects at this grade.

Mean accuracy at Grade 4 was analyzed with an analysis of variance with base frequency (high or low), surface frequency (high or low), and transparency (transparent or opaque) as the three within-subjects variables. There was a main effect of base frequency, $F(1,29)=29.71, p<.001, d=0.34$, and an interaction between transparency and surface frequency, $F(1,29)=13.85, p<.001$, that 
Deacon et al.: Do children see the danger in dangerous?

Table 1. Mean accuracy scores (standard deviations) in proportion correct for high and low base frequency and high and low surface frequency for each set of the transparent and opaque words for participants in Grades 4, 6, and 8

\begin{tabular}{|c|c|c|c|c|c|c|}
\hline & \multicolumn{2}{|c|}{ Grade 4} & \multicolumn{2}{|c|}{ Grade 6} & \multicolumn{2}{|c|}{ Grade 8} \\
\hline & $\begin{array}{c}\text { High } \\
\text { Surface }\end{array}$ & $\begin{array}{c}\text { Low } \\
\text { Surface }\end{array}$ & $\begin{array}{c}\text { High } \\
\text { Surface }\end{array}$ & $\begin{array}{c}\text { Low } \\
\text { Surface }\end{array}$ & $\begin{array}{c}\text { High } \\
\text { Surface }\end{array}$ & $\begin{array}{c}\text { Low } \\
\text { Surface }\end{array}$ \\
\hline \multicolumn{7}{|c|}{ Transparent } \\
\hline High base & $.79(.26)$ & $.70(.20)$ & $.95(.11)$ & $83(.15)$ & $.95(.09)$ & $.89(.11)$ \\
\hline Low base & $.67(.22)$ & $.61(.24)$ & $.82(.16)$ & $.80(.17)$ & $.93(.11)$ & $.83(.16)$ \\
\hline \multicolumn{7}{|c|}{ Opaque } \\
\hline High base & $.74(.26)$ & $.56(.26)$ & $.92(.12)$ & $.76(.17)$ & $.95(.12)$ & $.79(.17)$ \\
\hline Low base & $.72(.31)$ & $.48(.26)$ & $.91(.17)$ & $.69(.22)$ & $.95(.11)$ & $.84(.18)$ \\
\hline
\end{tabular}

qualified the main effects of transparency, $F(1,29)=11.80, p<.01, d=0.30$, and surface frequency, $F(1,29)=66.86, p<.001, d=0.62$. The main effects reflected the patterns for scores to be higher for the words with high than with low base or surface frequency and for transparent than for opaque items. The interaction between surface frequency and transparency arose because the effect of transparency (with greater accuracy for the transparent than for the opaque items) was significant for the words of low surface frequency, $t(29)=5.22, p<$ $.001, d=0.63$, but not for those of high surface frequency, $t(29)=0.07, n s$. The interaction between surface frequency and transparency suggests that the opacity of the bases within words has an impact on the reading of words with low surface frequency. Notably, the main effect of base frequency reflects increased accuracy for reading words with high than low base frequencies, regardless of the surface frequency or opacity.

Mean accuracy at Grade 6 was analyzed with an analysis of variance conducted with the data for the low surface frequency words. This had base frequency (high or low) and transparency (transparent or opaque) as the two within-subjects variables. There were main effects of both transparency, $F(1,30)=16.38, p<.001, d=$ 0.56 , and base frequency, $F(1,30)=7.48, p<.01, d=0.32$, with no interaction between the two variables $(p>.30)$. The main effects for the analysis of the data for the low surface frequency items reflected the tendencies for scores to be higher for the words of high than of low base frequency and for words of transparent than of opaque surface structure.

\section{Analyses of response time}

In accordance with Carlisle and Stone (2005), all responses for which reaction time as recorded by the microphone was accurate were analyzed. This included reaction times to both correct and incorrect pronunciations. The inclusion of reaction times to correct and incorrect items increases the comparability of results across grades 
Deacon et al.: Do children see the danger in dangerous?

Table 2. Response time (standard deviations) for high and low base frequency, high and low surface frequency, and transparent and opaque words (ms) for participants in Grades 4, 6, and 8

\begin{tabular}{|c|c|c|c|c|c|c|}
\hline & \multicolumn{2}{|c|}{ Grade 4} & \multicolumn{2}{|c|}{ Grade 6} & \multicolumn{2}{|c|}{ Grade 8} \\
\hline & $\begin{array}{l}\text { High } \\
\text { Surface }\end{array}$ & $\begin{array}{c}\text { Low } \\
\text { Surface }\end{array}$ & $\begin{array}{c}\text { High } \\
\text { Surface }\end{array}$ & $\begin{array}{c}\text { Low } \\
\text { Surface }\end{array}$ & $\begin{array}{c}\text { High } \\
\text { Surface }\end{array}$ & $\begin{array}{l}\text { Low } \\
\text { Surface }\end{array}$ \\
\hline \multicolumn{7}{|c|}{ Transparent } \\
\hline High base & $\begin{array}{c}1516 \\
(1040)\end{array}$ & $\begin{array}{c}1908 \\
(1116)\end{array}$ & $\begin{array}{l}1046 \\
(433)\end{array}$ & $\begin{array}{l}1302 \\
(575)\end{array}$ & $\begin{array}{c}828 \\
(297)\end{array}$ & $\begin{array}{l}1069 \\
(366)\end{array}$ \\
\hline Low base & $\begin{array}{l}1505 \\
(843)\end{array}$ & $\begin{array}{c}2428 \\
(1191)\end{array}$ & $\begin{array}{l}1059 \\
(457)\end{array}$ & $\begin{array}{l}1691 \\
(793)\end{array}$ & $\begin{array}{c}815 \\
(213)\end{array}$ & $\begin{array}{l}1236 \\
(414)\end{array}$ \\
\hline \multicolumn{7}{|c|}{ Opaque } \\
\hline High base & $\begin{array}{l}1593 \\
(881)\end{array}$ & $\begin{array}{l}1764 \\
(900)\end{array}$ & $\begin{array}{l}1035 \\
(342)\end{array}$ & $\begin{array}{l}1229 \\
(470)\end{array}$ & $\begin{array}{c}829 \\
(263)\end{array}$ & $\begin{array}{l}1024 \\
(328)\end{array}$ \\
\hline Low base & $\begin{array}{l}1690 \\
(978)\end{array}$ & $\begin{array}{c}2497 \\
(1560)\end{array}$ & $\begin{array}{l}1075 \\
(471)\end{array}$ & $\begin{array}{l}1705 \\
(946)\end{array}$ & $\begin{array}{c}889 \\
(421)\end{array}$ & $\begin{array}{l}1121 \\
(432)\end{array}$ \\
\hline
\end{tabular}

(as argued by Carlisle \& Stone), as analyses are based on similar numbers of items for each grade. Mean response times are shown in Table 2.

An ANOVA was conducted with reaction times, with grade as the betweensubjects variable $(4,6$, or 8$)$ and base frequency (high or low), surface frequency (high or low), and transparency (transparent or opaque) as the three within-subjects variables. There was a three-way interaction between base frequency, surface frequency and grade, $F(2,82)=7.09, p<.001$, that qualified three two-way interactions and three main effects: interactions between surface frequency and grade, $F(2,82)=4.28, p<.05$, between base frequency and grade, $F(2,82)=$ $7.15, p<.01$, and between base frequency and surface frequency, $F(2,82)=$ $52.66, p<.001$, and main effects of base frequency, $F(1,82)=62.42, p<$ .001 , surface frequency, $F(1,82)=106.87, p<.001$, and grade, $F(1,82)=$ 12.49, $p<.001$. A further two-way interaction was not qualified by any higher order interactions (all $p \mathrm{~s}>.25$ ): between transparency and surface frequency, $F(2,82)=7.85, p<.01$.

Considering first the three-way interaction, we examined the interaction between base frequency and surface frequency at each grade level separately. This showed main effects of base frequency $(F$ values $>37$, and all $p$ s $<.001)$ and of surface frequency $(F$ values $>10$, and all $p$ s $<.01)$ and an interaction between base frequency and surface frequency at each grade $(F$ values $>6$, and all $p$ s $<$ .02). Paired-sample $t$ tests at each grade revealed the same pattern of results at each grade. This was a pattern in which reaction times were faster to words with high than low base frequencies for the words of low surface frequency: Grade $4, t$ $(29)=6.80, p<.001, d=.55$; Grade $6, t(30)=4.96, p<.001, d=.65$; Grade 8 , $t(24)=3.19, p<.01, d=.36$, but not of high surface frequency: Grade $4, t(29)=$ 
Deacon et al.: Do children see the danger in dangerous?

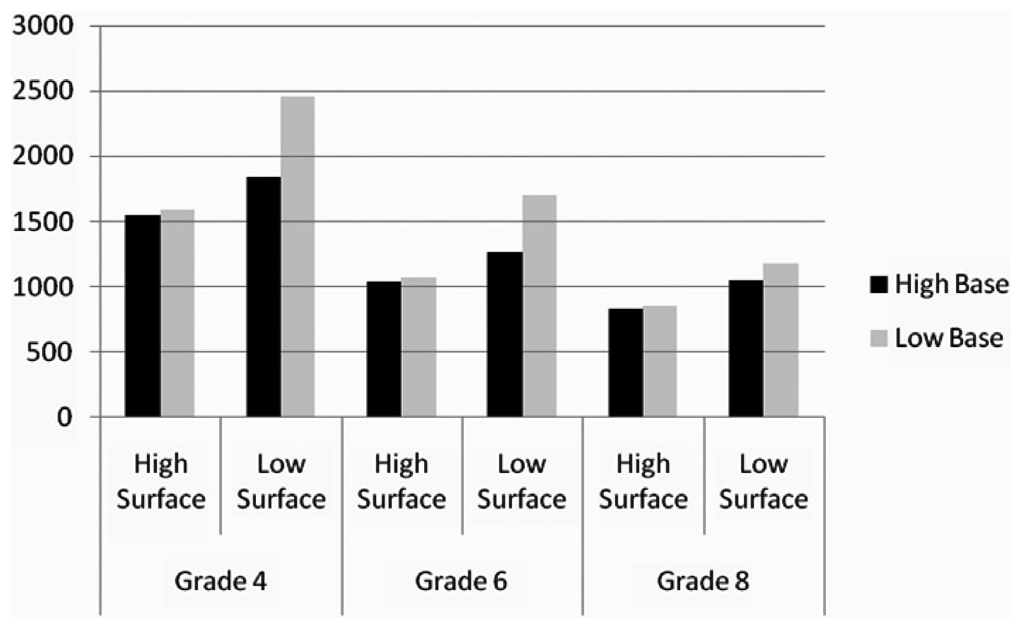

Figure 1. Mean response time for each grade as a function of base and surface frequency.

$0.80, n s$; Grade $6, t(30)=0.95, n s$; Grade $8, t(24)=1.37, n s$. The three-way interaction is likely to have arisen because the effect of the base frequency for the low surface frequency items (as demonstrated in the $d$ values) is far larger for the Grade 4 and 6 children than it is for the Grade 8 children. See Figure 1 for a visual description of the two-way interaction between base frequency and surface frequency at each grade level.

We then examined the two-way interaction between transparency and surface frequency. There was a trend for the response time for the opaque items to be longer than those for the transparent items for the high surface frequency items (means = 1149 and 1207, respectively), with the opposite pattern for the transparent items (means $=1637$ and 1590, respectively). These differences did not reach significance in the paired sample $t$ tests ( $t \mathrm{~s}<1.6$ and $p s>.13$ ). The interaction is more likely to have been caused by slight differences in the size of the surface frequency effect; the surface frequency effect was slightly greater for the transparent than for the opaque items, $t(84)=9.88, p<.001, d=0.63, t(84)=8.87, p<.001, d=$ 0.47 , respectively.

\section{DISCUSSION}

This study was designed to extend earlier investigations of children's sensitivity to the morphological structure of the words that they read. We asked children in Grades 4,6 , and 8 to read a set of 64 words that varied systematically in their surface and base frequencies and in the opacity of their base forms. The latter two of these manipulations provide insight into children's access to the bases contained in the derived words that they read. The results suggest that children's accuracy and speed in word reading is affected by the morphological structure of the words that they read. We discuss the results in relation to each of our variables of interest in turn, and we then relate these findings to current theories of reading development and adult lexical processing. 


\section{Effects of base frequency}

The results of our investigation of the effects of the base frequency variable on word reading accuracy and speed of a wide variety of derived forms extend prior findings (Mann \& Singson, 2003; see also Carlisle \& Stone, 2005). We found that children in Grade 4 were more likely to pronounce a word accurately if it had a base of high rather than low base frequency. This effect was consistent across words of varying surface frequency and degrees of transparency. For the children in Grade 6, base frequency effects emerged in the reading of the transparent and opaque low surface frequency items (with no such analyses possible for high surface frequency forms). Ceiling effects in the data for Grades 6 and 8 precluded developmental analyses comparing the grades, but the conducted analyses suggest clear effects of base frequency on accuracy in both Grades 4 and 6. The reaction time results indicate that there is relative consistency in the effects of base frequency across Grades 4, 6 , and 8. Children were faster at reading low surface frequency derived words with high than with low base frequencies, but this effect did not emerge for the high surface frequency words (shown in Figure 1). This effect was present across all grades, although it was greater in magnitude at Grades 4 and 6 than at Grade 8. This is a potentially intriguing developmental trend, in which there might be gradually diminishing effects of base frequency on reading speed. Notably, these are likely to persist in sensitive tasks into adulthood (see, e.g., Taft, 1979). The effects of base frequency on word reading accuracy (at least for the younger children) and reaction time reflects children's sensitivity to the morphological structure of the words that they read.

There is a glimmering of a divergence between the effects of base frequency on accuracy and speed. At Grade 4, base frequency increased reading speed of the low, but not high surface frequency words, but it increased accuracy of all types of words tested. The absence of an increase in reading speed for the high surface frequency words highlights the role that morphemic segmentation might play in achieving accurate word reading. At first, this might be effortful, resulting in no gains in reading speed. By Grade 8 , when word reading is relatively mature, the effects of morphemic processing might only emerge in reading speed. Our data on this point are not conclusive, particularly given ceiling effects in the Grade 8 data. It does point to the need to consider both accuracy and response time in analyses (as in Carlisle \& Stone, 2005).

\section{Effects of transparency of the base form}

Unlike the effects of frequency of the base form, the effects of its transparency are restricted to reading accuracy. At Grade 4, children were more accurate in reading words with transparent base structures when these words were of low (but not of high) surface frequency. At Grade 6, this effect emerged for all low surface frequency items (with no analyses possible for the high surface frequency items or for the Grade 8 children). In contrast to these analyses of accuracy, there was no consistent effect of the opacity of the base of the derived forms on reaction times. The absence of the effects of transparency on reaction time is perhaps surprising given its emergence in the reading of the middle school children in Carlisle and Stone's (2005) study. When examining the effects of morphemic complexity on children's response times, it is important to bear in mind Tyler and Nagy's 
(1989) discussion of the potentially opposing influences of morphemic complexity on reaction time. They argued that morphemic complexity might initially speed lexical access to the base form and it might then slow processing of the word due to the selection of the correct response among the multiple morphologically complex forms of the base. With respect to our specific conditions, it might be relatively easy (and fast) to recognize the presence of a transparent base form and this might speed overall pronunciation of the derived form. In contrast, words with opaque base forms might be more likely to be accessed as whole word forms, which is also suggested to be fast and efficient (e.g., Ehri, 2005). The speed of two such putative access routes might be similar when access to the base form is speeded, as might be the case for high frequency bases. Regardless of the specific instantiation of lexical access and word reading strategies, effects on reaction time are not necessary to demonstrate morphemic effects. At least children at Grades 4 and 6 were more accurate in reading words with transparent than opaque base structures when these forms had low surface frequencies, suggesting that the transparency of the base form can increase the likelihood of correct pronunciation at least in some cases.

\section{Implications of this research for models of reading development}

In her phase model, Ehri $(1998,2005)$ discusses the idea that common letter patterns might become consolidated in lexical memory during the consolidated alphabetic phase. In this phase, morphemic and nonmorphemic patterns (such as -ion and -ight, respectively) are given equal weighting, suggesting that the two might not be dissociated in processing (for more discussion on this point, see Carlisle \& Stone, 2005). The evidence presented here suggests that morphemes have an independent effect on reading. The presence of highly frequent or transparent morphemic units, in this case base forms, seems to increase accuracy rates, and the presence of high frequency base forms speeds of pronunciation of low frequency derived words. It seems then that the consolidation that Ehri discusses might occur, at least in part, at the level of base morphemes and that these potentially consolidated morphemes increase speed in reading low frequency derived words across Grades 4 to 8 . It would be important to look to younger readers to examine the beginning points of this consolidation.

Recent statistical explanations put forward in the spelling literature (see Pacton \& Deacon, 2008; Pollo, Treiman, \& Kessler, 2007) provide an alternative explanation of our findings. These approaches offer a means for the semantic information contained in base morphemes to gain additional weight in processing; this might occur through children's exposure to consistent sound and letter patterns in tandem with specific meanings. Such co-occurrences might be able to generate consistencies at the level of the linguistic concept of the morpheme. Repeated exposure, for example, to the words magic, magician, and magical, might permit the sounds of the base to become consolidated with its meaning and spelling. The idea of the binding of phonology, orthography, and semantics has also been articulated as a part of the lexical quality hypothesis (see, e.g., Perfetti, 2007). Manipulations of variables of semantic and phonological transparency in a graded manner (as in Gonnerman, Seidenberg, \& Andersen, 2007) would help to clarify interpretations in the future. 
Deacon et al.: Do children see the danger in dangerous?

In addition to these developmental models, we want to consider the similarity of some aspects of the results in our study with children to those with adults. The findings of the increase in word reading speed for words with high (in comparison to low) base frequencies across Grades 4 to 8 parallel those uncovered in adult priming studies (e.g., Meunier \& Segui, 1999). Such results are often viewed as supportive of a dual-route model (see, e.g., Baayen, Dijkstra, \& Schreuder, 1997; for a review, see Seidenberg \& Gonnerman, 2000). In dual-route approaches, there are two competing routes: one by which the word's full-form representation is accessed via the whole word and a decompositional route, in which the component morphemes are accessed separately. The results of our research might be interpreted as demonstrating that the recognition of whole high frequency derived forms is faster than decomposition into morphemic parts with the opposite pattern for the low frequency derived forms. Such approaches clearly need to be extended early into the development of reading processes to test their applicability in explaining the emergence of mature reading processes.

\section{FUTURE RESEARCH AND CONCLUSIONS}

One clear area for new research lies in investigating the effects of family size and of family frequency (e.g., Reichle \& Perfetti, 2003). Word forms vary in the number of morphologically related words (family size) and in the average frequency of these forms (family frequency), and both of these factors have been shown to affect adult lexical processing (e.g., Nagy, Anderson, Schommer, Scott, \& Stallman, 1989; Schreuder \& Baayen, 1997). There is one recent study showing that both of these variables have impacts on children's word reading (Carlisle \& Katz, 2006). This new investigation also pointed to the challenges of disentangling these effects from those of base frequency; in Carlisle and Katz's study, family frequency and size covaried systematically with base frequency. We calculated these values for the items in our own study according to the method outlined by Carlisle and Katz. These calculations were post hoc by necessity given these variables were not a part of our originally intended manipulations. We found that words with higher base frequencies and with higher surface frequencies also had larger family sizes. In terms of average family frequency, only base frequency varied with family frequency only for the transparent high surface frequency items. Nevertheless, these patterns point to similar problems to those encountered by Carlisle and Katz in dissociating the various frequency calculations. Clearly, this challenge has not yet been overcome in existing developmental research and systematic examination of each of these factors is an important next step.

At the same time, it would be important to examine the distinction between opaque items that involve phonological change alone (as is the case for healhealth) and those with phonological and orthographic changes (such as in agileagility). We included both types in this study, in part following on results from Carlisle (1988), suggesting similar accuracy in morphological awareness tasks with these two types of items. Nevertheless, it remains an open question as to the relative influence of these two factors in naming tasks.

There are several additional methodological considerations for future studies. The present study drew on a relatively wide range of suffixes. It would be useful 
Deacon et al.: Do children see the danger in dangerous?

for future studies to strategically manipulate variables for words with specific affixes, as it is possible that results vary across affixes (as in Bertram, Baayen, \& Schreuder, 2000). Another methodological consideration lies in the outcome metric. Following on Carlisle and Stone (2005) we analyzed response time to all words, regardless of whether they were correctly or incorrectly pronounced. This approach ensures that cross-grade comparisons are made on the basis of the same number of items (as argued by Carlisle \& Stone, 2005). In adult research (see e.g., Marslen-Wilson, Tyler, Waksler, \& Older, 1994), it is more common to examine reaction time only in cases when accuracy is above some minimal level (often $80 \%$ ), as would be the case for our results at Grade 8. Our finding that the base frequency and surface frequency interaction was similar across the grades supports the interpretation of the results for all items, regardless of the accuracy of their pronunciation. Nevertheless, it would be valuable for future studies to develop ways in which response times can be examined in methodologies yielding higher accuracy rates. Conversely, other studies could develop tasks with lower accuracies to permit a closer examination of effects on reading accuracy in the absence of ceiling effects.

The aim of this study was to specify whether children access the morphological structure of morphologically complex words that they encounter in print. It seems that they do. There was evidence of the effects of morphological structure on children's reading accuracy and time with some intriguing interactions across word type. These findings need to be followed up with fine-grained investigations to understand the ways in which the impact of morphological structure on word reading emerges.

\section{APPENDIX A}

List of morphologically complex words used in reading task and their frequencies (Freq.) according to Educator's Word Frequency Guide a and mean accuracies (Acc.) and response times $(R T)$ for each item (across grades)

\begin{tabular}{|c|c|c|c|c|c|c|c|c|c|}
\hline \multicolumn{5}{|c|}{ Transparent } & \multicolumn{5}{|c|}{ Opaque } \\
\hline $\begin{array}{l}\text { Base. } \\
\text { Freq. }\end{array}$ & Surface & Freq. & Acc. & RT & $\begin{array}{l}\text { Base } \\
\text { Freq. }\end{array}$ & Surface & Freq. & Acc. & RT \\
\hline \multicolumn{10}{|c|}{ High Base, High Surface Frequency Words } \\
\hline \multirow[t]{2}{*}{70} & Addition & 100 & .91 & 1046 & 301 & Ability & 99 & .94 & 988 \\
\hline & Completely & 79 & .89 & 1045 & & Death & 152 & .95 & 916 \\
\hline \multirow[t]{2}{*}{107} & Dangerous & 73 & .95 & 844 & 133 & Decision & 58 & .94 & 1253 \\
\hline & Development & 126 & .89 & 1232 & & Direction & 127 & .89 & 1205 \\
\hline \multirow[t]{2}{*}{69} & Directly & 97 & .81 & 1266 & 97 & Electricity & 78 & .79 & 1222 \\
\hline & Effective & 58 & .87 & 1521 & & Industrial & 75 & .78 & 1410 \\
\hline \multirow[t]{2}{*}{106} & Generally & 110 & .81 & 1202 & 78 & Natural & 184 & .81 & 1062 \\
\hline & Leader & 65 & .99 & 876 & & Production & 91 & .81 & 1105 \\
\hline 113 & & 88.5 & .89 & 1129 & 127 & & 108 & .86 & 1145 \\
\hline
\end{tabular}


Deacon et al.: Do children see the danger in dangerous?

Appendix A (cont.)

\begin{tabular}{|c|c|c|c|c|c|c|c|c|c|}
\hline \multicolumn{5}{|c|}{ Transparent } & \multicolumn{5}{|c|}{ Opaque } \\
\hline $\begin{array}{l}\text { Base. } \\
\text { Freq. }\end{array}$ & Surface & Freq. & Acc. & RT & $\begin{array}{l}\text { Base } \\
\text { Freq. }\end{array}$ & Surface & Freq. & Acc. & RT \\
\hline \multicolumn{10}{|c|}{ Low Base, High Surface Frequency Words } \\
\hline \multirow[t]{2}{*}{1} & Available & 105 & .79 & 1235 & 3 & Education & 122 & .82 & 1302 \\
\hline & Computer & 53 & 1 & 822 & & Health & 102 & .96 & 842 \\
\hline \multirow[t]{2}{*}{1} & Equipment & 90 & .87 & 1158 & 2 & Population & 136 & .86 & 1198 \\
\hline & Especially & 150 & .44 & 1216 & & Position & 133 & .71 & 1453 \\
\hline \multirow[t]{2}{*}{1} & Eventually & 53 & .86 & 1213 & 0.15 & President & 161 & .89 & 1249 \\
\hline & Medical & 60 & .91 & 1259 & & Situation & 78 & .76 & 1631 \\
\hline \multirow[t]{2}{*}{0.61} & Normal & 73 & .93 & 811 & 0.02 & Television & 69 & .95 & 909 \\
\hline & Political & 128 & .59 & 1471 & & Temperature & 123 & .87 & 1205 \\
\hline 0.84 & & 89 & .80 & 1148 & 1.06 & & 115.5 & .85 & 1223 \\
\hline
\end{tabular}

\section{High Base, Low Surface Frequency Words}

\begin{tabular}{llllllllll}
\hline 106 & Developer & 1 & .87 & 1459 & 242 & Closure & 0.40 & .91 & 1262 \\
& Dryness & 1 & .96 & 1160 & & Imaginable & 1 & .88 & 1303 \\
155 & Follower & 1 & .81 & 1140 & 78 & Inclusion & 0.72 & .71 & 1393 \\
& Locally & 1 & .85 & 1196 & & Objection & 3 & .89 & 1226 \\
144 & Purposeful & 1 & .51 & 1749 & 116 & Sociable & 0.89 & .73 & 1700 \\
& Serviceable & 0.74 & .48 & 2224 & & Studious & 0.43 & .35 & 1611 \\
107 & Traveler & 1 & .98 & 1200 & \multirow{2}{*}{118} & Totality & 0.72 & .20 & 1230 \\
& Wonderment & 0.54 & .94 & 1571 & & Wondrous & 1 & .91 & 1117 \\
& Developer & 1 & .87 & 1459 & & Closure & 0.40 & .91 & 1262 \\
& Dryness & 1 & .96 & 1160 & & Imaginable & 1 & .88 & 1303 \\
124 & Follower & 1 & .81 & 1140 & 250 & Inclusion & 0.72 & .71 & 1393 \\
& Locally & 1 & .85 & 1196 & & Objection & 3 & .89 & 1226 \\
111 & Purposeful & 1 & .51 & 1749 & \multirow{2}{*}{101} & Sociable & 0.89 & .73 & 1700 \\
& Serviceable & 0.74 & .48 & 2224 & & Studious & 0.43 & .35 & 1611 \\
73 & Traveler & 1 & .98 & 1200 & \multirow{2}{*}{73} & Totality & 0.72 & .20 & 1230 \\
& Wonderment & 0.54 & .94 & 1571 & & Wondrous & 1 & .91 & 1117 \\
116.6 & & 0.91 & .80 & 1462 & \multirow{2}{*}{143.7} & & 1.02 & .70 & 1355 \\
& & & & & & & & & \\
\hline
\end{tabular}

Low Base, Low Surface Frequency Words

\begin{tabular}{lllllllllll}
\hline 0.78 & Avidly & 0.33 & .47 & 1910 & 1 & Agility & 0.97 & .71 & 1773 \\
& Cohesiveness & 0.14 & .64 & 3254 & & Assertion & 2 & .36 & 2183 \\
1 & Cowardly & 1 & .94 & 1274 & 2 & Disruption & 1 & .81 & 1588 \\
& Diligently & 1 & .55 & 2672 & & Irritable & 1 & .61 & 1586 \\
1 & Dismissal & 1 & .91 & 1242 & 1 & Mimic & 1 & .85 & 1353 \\
& Impairment & 1 & .87 & 1744 & & Termination & 1 & .76 & 1635 \\
0.95 & Mower & 3 & .84 & 1118 & \multirow{2}{*}{1} & Traumatic & 0.69 & .69 & 1819 \\
& Offender & 1 & .73 & 1478 & & Viscosity & 0.53 & .46 & 2280 \\
0.93 & & 1.06 & .74 & 1837 & \multirow{2}{*}{1.41} & & 1.03 & .66 & 1777 \\
\hline \hline
\end{tabular}

${ }^{a}$ Zeno (1995). 
Applied Psycholinguistics 32:3

Deacon et al.: Do children see the danger in dangerous?

\section{ACKNOWLEDGMENTS}

We thank the participating teachers and students in the Annapolis Valley School Board in Nova Scotia for their help with this research. We also acknowledge the support of a Social Sciences and Humanities Research Council grant to the first (S.H.D.) and third (J.R.K.) authors.

\section{REFERENCES}

Anglin, J. M. (1993). Vocabulary development: A morphological analysis. Monographs of the Society for Research in Child Development, 58(10, Serial No. 238), 1-165.

Baayen, R. H., Dijkstra, T., \& Schreuder, R. (1997). Singulars and plurals in Dutch: Evidence for a parallel dual-route model. Journal of Memory and Language, 37, 94-117.

Bertram, R., Baayen, R. H., \& Schreuder, R. (2000). Effects of family size for complex words. Journal of Memory and Language, 42, 390-405.

Carlisle, J. F. (1988). Knowledge of derivational morphology and spelling ability in fourth, sixth, and eighth graders. Applied Psycholinguistics, 9, 247-266.

Carlisle, J. F. (2000). Awareness of the structure and meaning of morphologically complex words: Impact on reading. Reading and Writing, 12, 169-190.

Carlisle, J. F., \& Katz., L. A. (2006). Effects of word and morpheme familiarity on reading of derived words. Reading and Writing, 19, 669-693.

Carlisle, J. F., \& Stone, C. A. (2005). Exploring the role of morphemes in word reading. Reading Research Quarterly, 40, 428-449.

Ehri, L. C. (1998). Grapheme-phoneme knowledge is essential for learning to read words in English. In J. L. Metsala \& L. C. Ehri (Eds.), Word recognition in beginning literacy (pp 3-40). Mahwah, NJ: Erlbaum.

Ehri, L. C. (2005). Learning to read words: Theory, findings, and issues. Scientific Studies of Reading, 9, 167-188.

Gonnerman, L. M., Seidenberg, M. S., \& Andersen, E. S. (2007). Graded semantic and phonological similarity effects in priming: Evidence for a distributed connectionist approach to morphology. Journal of Experimental Psychology: General, 136, 323-345.

Jarvis, B. (2000). DirectRT (Version 2000.4.9) [Computer software]. New York: Empirisoft.

Lee, C. J. (2003). Evidence-based selection of word frequency lists. Journal of Speech-Language Pathology and Audiology, 27, 170-173.

Mann, V., \& Singson, M. (2003). Linking morphological knowledge to English decoding ability: Large effects of little suffixes. In E. M. H. Assink \& D. Sandra (Eds.), Reading complex words: Cross-language studies (pp. 1-25). New York: Kluwer Academic.

Marlsen-Wilson, W. D., Tyler, L. K., Waksler, R., \& Older, L. (1994). Morphology and meaning in the English mental lexicon. Psychology Review, 101, 3-33.

Meunier, F., \& Segui, J. (1999). Morphological priming effect: The role of surface frequency. Brain and Language, 68, 54-60.

Nagy, W. E., \& Anderson, R. (1984). The number of words in printed school English. Reading Research Quarterly, 19, 304-330.

Nagy, W. E., \& Anderson, R., Schommer, M., Scott, J. A., \& Stallman, A. C. (1989). Morphological families and word recognition. Reading Research Quarterly, 24, 262-282.

Nagy, W. E., Osborn, J., Winsor, P., \& O'Flahavan, J. (1993). Structural analysis: Some guidelines for instruction. In F. Lehr \& J. Osborn (Eds.), Reading, language, and literacy: Instruction for the twenty-first century (pp. 45-58). Hillsdale, NJ: Erlbaum.

Pacton, S., \& Deacon, S. H. (2008). The timing and mechanisms of children's use of morphological information in spelling: A review of evidence from French and English. Cognitive Development, $23,339-359$.

Perfetti, C. A. (2007). Reading ability: Lexical quality to comprehension. Scientific Studies of Reading, $11,357-383$.

Pollo, T. C., Treiman, R., \& Kessler, B. (2007). Three perspectives on spelling development. In E. J. Grigorenko \& A. Naples (Eds.), Single-word reading: Cognitive, behavioral, and biological perspectives (pp. 175-189). Mahwah, NJ: Erlbaum. 
Deacon et al.: Do children see the danger in dangerous?

Reichle, E., \& Perfetti, C. A. (2003). Morphology in word identification: A word-experience model that accounts for morpheme frequency effects. Scientific Studies of Reading, 7, 219-237.

Schreuder, R., \& Baayen, R. H. (1997). How complex simplex words can be. Journal of Memory and Language, 36, 118-139.

Seidenberg, M. S., \& Gonnerman, L. M. (2000). Explaining derivational morphology as the convergence of codes. Trends in Cognitive Sciences, 4, 353-361.

Taft, M. (1979). Recognition of affixed words and the word frequency effect. Memory \& Cognition, 7 , 263-272.

Tyler, A., \& Nagy, W. (1989). The acquisition of English derivational morphology. Journal of Memory and Language, 28, 649-667.

Woodcock, R. (1998). Woodcock Reading Mastery Tests—Revised. Circle Pines, MN: American Guidance Services.

Zeno, S. (Ed.): 1995. The Educator's Word Frequency Guide. Brewster, NJ: Touchstone Applied Science Associates. 